\title{
QUANDO OS SONHOS DE DESENVOLVIMENTO PRODUZEM MONSTROS $^{1}$ : a violência como parte da estratégia de modernização no campo brasileiro
}

\author{
WHEN DEVELOPMENT DREAMS PRODUCE MONSTERS: \\ violence as part of the modernization strategy in the Brazilian \\ countryside
}

\author{
Laura dos Santos Rougemont \\ Doutoranda no Programa de Pós-Graduação em Geografia da Universidade Federal Fluminense (UFF) \\ lsrougemont@gmail.com
}

\section{Resumo}

A partir da enunciação de alguns casos de assassinatos e ameaças a lideranças e membros de comunidades tradicionais, esse artigo pretende se debruçar sobre três aspectos, com o intuito de contribuir para a discussão da Geografia da violência no campo no Brasil: o primeiro deles se pauta numa leitura de algumas análises sobre a ideia de "fronteira", considerada o lócus de materialização de conflitos no campo; o segundo aspecto busca evidenciar os elementos mais pragmáticos em torno dos negócios de terra e dos projetos de desenvolvimento observados em áreas de fronteira do capital no Brasil, que conjugam táticas modernas e coloniais para viabilizar mecanismos de acumulação; por fim, pretende-se apontar elementos acerca da violência no campo, utilizando-se de dados apresentados pela Comissão Pastoral da Terra (CPT) em 2017. Neste sentido, destacamse elementos da conflitividade da terra, tendo como base algumas formas de operação da violência, seus agentes, vítimas, bem como a distribuição regional dos casos, concentrados em áreas do Cerrado e da Amazônia Legal.

Palavras-chave: Fronteira. Violência. Desenvolvimento.

\begin{abstract}
Based on the enunciation of some cases of murders and threats to leaders and members of traditional communities, this article intends to focus on three aspects, in order to contribute to the discussion of the Geography of violence in the countryside in Brazil: the first of them is based in a reading of some analyzes on the idea of "frontier", considered the locus of materialization of conflicts in the countryside; the second aspect seeks to highlight the pragmatic elements surrounding land deals and development projects observed in frontier areas in Brazil, which combine modern and colonial tactics to enable mechanisms of accumulation; finally, it is intended to point out elements around violence in the countryside, using data presented by the Pastoral Land Commission (CPT) in 2017. In this sense, some elements of land conflits are emphasized, based on some forms of

\footnotetext{
${ }^{1}$ Este título é inspirado em uma passagem escrita por Vladimir Safatle no texto "Lama e tiros", publicado no dia $1^{\circ}$ de fevereiro de 2019, no jornal Folha de São Paulo (online).
} 
violence operation, agents, victims, as well as the regional distribution of cases, concentrated in Cerrado and Legal Amazon areas.

Keywords: Frontier. Violence. Development.

"Antevi o futuro e comprei."

(Euclides de Carli, latifundiário piauiense)

\section{Os "monstros": registros introdutórios}

No dia $1^{\circ}$ de novembro de 2014, no estado do Mato Grosso do Sul, nas imediações do município de Dourados - às margens da rodovia BR-163 - foi encontrado o corpo da indígena Kaiowá Marinalva Manoel, de 27 anos, morta a facadas. Marinalva era uma importante liderança na luta pela demarcação da Terra Indígena (TI) Nu Verá e integrava o Grande Conselho Guarani-Kaiowá da Aty Guasu. Ela havia comparecido em Brasília dias antes, manifestando repúdio à decisão do Supremo Tribunal Federal (STF) de anular o processo de demarcação de outra terra indígena guarani vizinha, a TI Guyraroká. De acordo com a Comissão Pastoral da Terra (2014), além de protestar contra a decisão do Supremo, os indígenas denunciaram o aumento da violência direta e indireta praticada por fazendeiros contra suas terras. Segundo o relatório elaborado pela Organização Não Governamental (ONG) Repórter Brasil (2013), os problemas ambientais que incidem nas terras indígenas guaranis são inúmeros. Um dos principais efeitos da invasão por fazendeiros tem sido a devastação da mata nativa. Cabe mencionar que, em 2010, nas proximidades da TI Guyraroká, instalou-se a usina sucroalcooleira Nova América, adquirida por uma das maiores empresas do ramo no Brasil, a Cosan, hoje denominada Raízen Caarapó S.A. Açúcar e Álcool. O novo nome decorre de uma fusão entre a empresa e a petroleira holandesa Shell.

Em 07 de abril de 2016, na Bahia, Rosivaldo Ferreira da Silva, mais conhecido como cacique Babau Tupinambá, e seu irmão, José Aelson Jesus da Silva, o Teity Tupinambá, foram presos pela Polícia Militar, no município de Olivença, no extremo sul do estado. Os irmãos indígenas, residentes da aldeia Gravatá, na TI Tupinambá de Olivença, Serra do Padeiro - que há anos aguarda pela definitiva demarcação - vinham denunciando um crime ambiental na TI: a retirada ilegal de areia. De acordo com a CPT (2016), a aldeia Gravatá é uma das áreas exaustivamente exploradas e degradadas por 
Quando os sonhos de desenvolvimento produzem monstros: a violência como parte da estratégia de modernização no campo brasileiro

sete mineradoras da região de Ilhéus, dentre elas a Areal Paraíso, a Areal Bela Vista e a Areal Guanabara. Conforme informações do Conselho Indigenista Missionário-CIMI (2016), há um recorrente processo de violência por parte do Estado, de fazendeiros e de pistoleiros contra os Tupinambá na região, que vão desde prisões arbitrárias, passando por torturas, destruição de casas e outros equipamentos comunitários, abuso de força policial, dentre outras práticas.

Nilce de Souza Magalhães, Nicinha, teve seu corpo encontrado no dia 21 de junho de 2016, no lago da barragem da usina hidrelétrica de Jirau, em Porto Velho (RO), a 400 metros do local onde morava. Ela era pescadora, filha de seringueiros e ativista do Movimento dos Atingidos por Barragens (MAB). Suas mãos e braços estavam amarrados a pedras que as mantinham dentro da água. Diretamente atingida pela construção de Jirau, Nicinha lutava contra a violação de direitos humanos dos atingidos e não reassentados pela usina. Já havia feito denúncias que envolviam a atividade pesqueira e os impactos da construção da hidrelétrica, as quais viraram inquéritos no Ministério Público (PRAGMATISMO POLÍTICO, n2016).

No Projeto de Assentamento (PA) Areia, a quarenta quilômetros do município de Trairão, no oeste do Pará, o casal de plantadores de frutas Osvalinda e Daniel Pereira sofrem intimidações e perseguições durante a noite. Homens armados, encapuzados e de moto rodeiam a casa dos dois, a mando de madeireiros daquela região. O casal está jurado de morte por não colaborar com a extração ilegal de árvores de alto valor comercial, conforme aponta o portal do Instituto Humanitas Unisinos-IHU (2016). Os madeireiros usam os lotes dos assentados como passagem para caminhões transportadores de toras e oferecem pagamento em troca da autorização da travessia. Segundo o IHU, a relação entre madeireiros e agricultores familiares na região vem se agravando devido aos planos de construção da Usina Hidrelétrica (UHE) de São Luiz do Tapajós. A estatal Eletrobras lidera o consórcio de empresas que têm interesse na concessão, e os grupos franceses EDF e GDF Suez são possíveis sócios do empreendimento. Além da UHE, outro conjunto de obras - que inclui rodovia, ferrovia, hidrovia e portos fluviais - pretende reconfigurar o território do oeste do Pará, com a intenção de agilizar o transporte de grãos da região Centro-oeste, maior produtora de soja e milho do Brasil (IHU, 2016).

De acordo com a Secretaria de Segurança Pública de Mato Grosso (Sesp), no dia 20 de abril de 2017, durante a semana em que se rememoravam os 21 anos do Massacre 
Quando os sonhos de desenvolvimento produzem monstros: a violência como parte da estratégia de modernização no campo brasileiro

de Eldorado dos Carajás, em Colniza (MT), ocorreu o assassinato de pelo menos dez moradores do assentamento Taquaraçu do Norte, localizado próximo ao Distrito de Guariba - a 1.065km de Cuiabá. Segundo informações enviadas à Secretaria, homens encapuzados invadiram o terreno do assentamento e assassinaram um grupo de pessoas (BRASIL DE FATO, 2017). Dados da CPT apontam que o conflito na região perdura desde junho de 2004, quando 185 famílias do assentamento foram expulsas por homens armados, que também destruíram suas plantações. O suspeito pela expulsão dizia ter comprado as terras que estavam sob posse dos trabalhadores desde 2002, reunidos na Cooperativa Agrícola Mista de Produção Roosevelt (Cooperosevelt). Estas terras correspondiam a 42.715 hectares, que foram concedidos para reintegração de posse, em benefício da cooperativa, pelo Juiz da Comarca de Colniza. Após este evento, em 2007, de acordo com a ANDES-SN (2017), pelo menos 10 trabalhadores foram vítimas de torturas e cárcere privado e outros 3 foram assassinados. Os responsáveis pela violência são fazendeiros da região que atuam especialmente na extração ilegal de madeira.

O povo indígena Gamela fez mais uma tentativa de retomada de seus territórios tradicionais no estado do Maranhão, como forma de pressionar a Fundação Nacional do Índio (FUNAI) a iniciar o processo de demarcação das terras. Assim, no dia 28 de abril de 2017, eles ocuparam a contígua área da aldeia Cajueiro Piraí, retomando uma área incidente da terra indígena, localizada ao fundo da aldeia Nova Vila e usada para a criação de búfalos e gado (CONGRESSO EM FOCO, 2017). De acordo com o Conselho Indigenista Missionário (CIMI), a área reivindicada é pública, doada aos Gamela desde o período colonial, em 1759. No entanto, o território vem sendo invadido e grilado, forçando os Gamela a se confinarem em um espaço cada vez menor. Atualmente, mais de 700 famílias vivem numa área de apenas 530 hectares, sofrendo com a falta de espaço para a prática da agricultura, com a grilagem e com a destruição de árvores e plantas utilizadas na alimentação (açaizais e gurimãs). No dia 30 de abril de 2017, durante a desocupação de seu território tradicional no Povoado das Baías, em Viana (MA) - visto que os indígenas temiam justamente ofensivas de fazendeiros da região - 22 indígenas terminaram feridos numa ação criminosa; dentre eles estavam crianças e préadolescentes. Alguns foram baleados, outros tiveram cortes com facões, traumas e escoriações provocadas por pauladas e pedradas, cercas de arame farpado, espinhos, além de dois indígenas terem as mãos amputadas e um deles também ter os joelhos cortados 
Quando os sonhos de desenvolvimento produzem monstros: a violência como parte da estratégia de modernização no campo brasileiro

nas articulações. Tal brutalidade foi protagonizada por homens armados, representantes de fazendeiros e capangas da região que, acompanhados de uma viatura da polícia, realizaram os ataques (CIMI, 2017).

Mais uma vez no Pará, os meses de abril e maio de 2017 também foram marcados por ameaças e assassinatos. Conforme denúncia do MST, ameaças de morte se intensificaram em acampamentos do Sul e do Sudeste do estado. Maria Raimunda César, militante do MST em Marabá, aponta que no dia 15 de abril de 2017 foram disparados tiros em direção ao acampamento da juventude, na Curva do $S$, da rodovia PA-150, entre Marabá e Eldorado dos Carajás. Dois dias depois, ela própria foi ameaçada de morte (BRASIL DE FATO, 2017). Pouco menos de um mês antes, Waldomiro Pereira também havia sido baleado dentro do lote onde vivia, no assentamento 17 de abril, em Paraupebas (PA). O assentado foi levado ao hospital ainda com vida, mas em 20 de março cinco homens armados renderam os seguranças do hospital onde ele estava internado e assassinaram Pereira na UTI. No dia 04 de maio de 2017, a trabalhadora e sindicalista Kátia Martins, de 43 anos, foi executada com cinco tiros numa emboscada ocorrida dentro da própria casa, no Assentamento $1^{\mathrm{o}}$ de Janeiro, no nordeste paraense, perto de Belém. No dia seguinte, na Fazenda Serra Norte, em Eldorado dos Carajás, Eduardo Soares da Costa também foi torturado e morto.

Em 2018, a brutalidade continuou. Em 12 de março, Paulo Sérgio Almeida Nascimento foi assassinado a tiros em Barcarena (PA), na zona rural do município. Segundo o site Amazônia Real (2019), sua atuação como segundo-tesoureiro da Associação dos Caboclos, Indígenas e Quilombolas da Amazônia (Cainquiama) tinha um histórico de denúncias contra vazamentos de bacias de rejeitos da Hydro-Alunorte, "a maior refinaria de alumínio do mundo fora da China", conforme o site oficial da própria empresa. Pouco mais de um mês, em 15 de abril, foi a vez da liderança quilombola Nazildo dos Santos Brito, de 33 anos. Nazildo residia na comunidade Turê III, no nordeste do Pará, entre Tomé-Açu e Acará, e vinha sofrendo ameaças por denunciar crimes ambientais na região. O fazendeiro José Telmo Zani, assassino do quilombola, fazia extração ilegal de madeira dentro do território e ameaçara Nazildo outras vezes antes de matá-lo.

A 50 quilômetros da rodovia BR 422 (Transcametá), na altura do município de Baião, nordeste do Pará, outra militante do MAB foi degolada por arma branca na noite 
Quando os sonhos de desenvolvimento produzem monstros: a violência como parte da estratégia de modernização no campo brasileiro

do dia 21 de março de 2019, com suspeitas de estupros e torturas. De acordo com o site Amazônia Real (2019), Dilma Ferreira da Silva, de 45 anos, foi morta junto com seu marido, Claudionor Costa da Silva, 43 anos, e Hilton Lopes, 38 anos, um assentado. Todos os três residiam no Assentamento Salvador Allende, criado pelo Instituto Nacional de Colonização e Reforma Agrária (Incra) na área da antiga fazenda Piratininga, ocupada por mais de 400 famílias sem-terra há mais de 12 anos. Desde o início, o local sofreu com ataques de pistoleiros e conflitos com madeireiros, além de ameaças constantes. As famílias sempre denunciaram conflitos agrários e desmatamento ilegal na região.

$\mathrm{O}$ registro sequencial e angustiante de casos de violência é somente uma estratégia de escrita. Já a repetição exaustiva de uso da violência é uma estratégia do capital em sua essência, como já nos apontaram há tanto tempo Karl Marx e Rosa Luxemburgo.

O texto que aqui está pretende contribuir para o debate em torno da "Geografia da Violência no campo brasileiro"2 e identifica, tendo por base os cadernos de conflitos no campo no Brasil, da CPT e outras publicações correlatas e fontes midiáticas, que há um acirramento de conflitos no campo a partir do golpe de estado de 2016 (coincidentemente o ano em que iniciamos esta pesquisa), revelando, desde então, um cenário devastador para as comunidades rurais (camponeses, trabalhadores rurais e povos e comunidades tradicionais), com um aumento exponencial de assassinatos e ameaças de morte, mas também de violências outras que muitas vezes são subnotificadas.

Para articular as conexões entre o novo-velho padrão de desenvolvimento no campo, que tem a violência como um de seus pilares, neste artigo, partimos de alguns pressupostos: compreendemos a fronteira (territorial e capitalista) como lócus do conflito e, por isso, na próxima parte, nos debruçamos a enunciar alguns imaginários e teorias sobre a fronteira; adiante, entendemos que há, neste momento histórico-geográfico, elementos em jogo dentro das propostas de negócios de terras no Brasil e, por esta razão, discutimos a processos de estrangeirização de terras, especialmente nas áreas de Cerrado e da Amazônia, com o intuito de elaborar o caráter pragmático da fronteira capitalista no campo hoje; por fim, partimos do entendimento de que a violência é algo inerente ao

\footnotetext{
${ }^{2}$ Carlos Walter Porto Gonçalves, Marco Mitidiero ou Carlos Alberto Feliciano já vêm desenvolvendo pesquisas sobre os conflitos e a violência no campo, fundamentados em dados registrados pela Comissão Pastoral da Terra (CPT), especialmente a partir dos cadernos de conflitos no campo, publicados anualmente desde 1985.
} 
Quando os sonhos de desenvolvimento produzem monstros: a violência como parte da estratégia de modernização no campo brasileiro

desenvolvimento e, portanto, realiza-se como parte inseparável dos mecanismos acionados pelos agentes "modernizadores", atuando de forma combinada aos processos de acumulação no campo - elementos que apontamos na terceira e última parte deste artigo, tendo como base alguns dados da CPT sobre conflitos no campo em 2017.

\section{Os "sonhos"}

Os debates em torno da noção de "fronteira" foram e são realizados em diversas áreas das Ciências Sociais e Humanas, tendo como destaque os estudos na Antropologia, na Sociologia, nas Ciências Políticas, na Economia, na História, na Literatura e na Comunicação Social - nestas duas últimas a partir de romances e ensaios escritos por literatos e jornalistas. A fronteira é também objeto de debate do qual se ocupa a Geografia, tanto da perspectiva dos estudos de Geopolítica, de Geografia da População - com enfoque sobre o tema das Migrações - da Geografia do Trabalho - em se tratando da precarização do trabalho na fronteira - quanto, por exemplo, da Geografia Cultural - nos debates em torno da construção de identidades - isto apenas para situar alguns casos. Certo é que independentemente do foco de análise de cada um destes campos, a fronteira tem sido uma questão-chave da leitura da formação histórica e geográfica, permitindo analisar desdobramentos econômicos, sociais, jurídicos, ambientais, agrários, dentre outros.

De início, para analisar a origem das diversas violências imbricadas com a questão da terra e do território, consideramos ser relevante apontar alguns imaginários e/ou teorias a respeito da fronteira, entendendo a fronteira, em termos territoriais e capitalistas, como lócus de materialização de conflitos. Se o reconhecimento de que o movimento de abertura de fronteiras consiste em sucessivas expansões "ao infinito e além”, a discussão de fronteira caminha de forma indissociável com a questão da terra, sendo, portanto, a nosso ver, imprescindível discutir as teorias da fronteira para pensar o campo dos estudos agrários e de conflitos socioterritoriais hoje. Dito isso, neste tópico, pretende-se fazer uma releitura de algumas perspectivas sobre este tema.

Otávio Velho (1972; 1979), um dos maiores estudiosos brasileiros no tema, tendo como foco os estudos nas fronteiras amazônicas, buscou compreender os usos e simbolismos na/da fronteira no capitalismo, assim como seus desdobramentos para a 

a violência como parte da estratégia de modernização no campo brasileiro

construção e desconstrução do campesinato. Ao discutir perspectivas sobre a fronteira em outros países, Velho (1979) relembra George Foster (1967) que, ao analisar as fronteiras norte-americanas, aborda a ideia de que a sociedade camponesa vê a terra como um fator limitado. Essa imagem da riqueza e da natureza como "bens limitados", para Foster, resulta do fato de que os camponeses têm tendência a serem "tradicionalistas e conservadores": em outras palavras, os camponeses seriam avessos ao progresso.

Ainda segundo Foster, dentro desta lógica, o desenvolvimento só seria possível a partir da mudança da visão do camponês e do seu universo social e econômico limitado para um cenário de oportunidades num sistema aberto, que permita sua expansão e tomadas de iniciativa, ou seja, para uma perspectiva da terra como valor ilimitado. Velho (1979) compreende tal proposição como uma oposição entre a visão camponesa interpretada como "restritiva" - e a visão capitalista - interpretada pelo viés do acúmulo de riqueza sempre crescente. Nesta última ótica, a natureza é vista, em geral, como provedora de bens infinitos. Para o autor, por sua vez, a busca pelo progresso estaria diretamente implicada na expansão das fronteiras ou, seja, na busca desenfreada pela exploração da natureza.

Em coerência com esta percepção e corroborando com a perspectiva mais progressista da terra vista como de valor ilimitado, isso justificaria, na prática, a expropriação camponesa, permitindo que a fronteira viabilizasse o domínio de outro universo de relações e práticas que, por sua vez, possibilitariam que caminhos fossem abertos para a expansão e o acúmulo de riquezas. Os camponeses, com suas ideias "tradicionais e conservadoras" seriam passíveis de exclusão dentro deste quadro; afinal, o progresso é uma emergência.

O lócus por excelência da terra "ilimitada" é, obviamente, a fronteira. Em
outras palavras, a fronteira é um lócus privilegiado para uma ideologia clássica
de laissez-faire em condições tais que de fato existe uma possibilidade ampla
para pelo menos um certo grau de avanço pessoal comparado com situações
anteriores. Dada a importância da ideologia da fronteira na sociedade norte-
americana, é provável que essa visão estivesse por detrás da formulação
original de Foster. Embora na prática, mesmo na fronteira, a terra não esteja
inteiramente aberta a todos sem limite algum, pode representar uma tal imagem
ideológica quando contrastada com outras situações camponesas. (VELHO,
1979, p.93).

Isso significa, no caso norte-americano, que o avanço do domínio sob terras ainda "desocupadas" (eis o movimento de fronteira) carrega ao menos ideologicamente a 
Quando os sonhos de desenvolvimento produzem monstros: a violência como parte da estratégia de modernização no campo brasileiro

ideia de ascensão, de progresso e desenvolvimento, o que proporcionaria uma melhora das condições materiais de indivíduos e da sociedade como um todo. A fronteira, então, é apontada como o lugar onde o camponês ascende socialmente e diminui a sua subordinação. Nesta perspectiva, era necessário o desenvolvimento das tendências capitalistas e de fronteira para que o campesinato se modernizasse - o que para Velho é a base fundamental do capitalismo autoritário, já que o autoritarismo se vale do controle/dominação das fronteiras como elemento importante para a promoção do desenvolvimento (VELHO,1979). Em complementaridade a esta visão, Becker (1988) afirma que há um mito sobre a fronteira que a põe em correspondência ao lócus de realização do capitalismo utópico, criando nexos entre uma colonização espontânea e processos históricos mais amplos desembocados a partir desta expansão.

Já para Musumeci (1984) - citada por Becker (1988) - no Brasil:

[...] a fronteira pode ser entendida como o espaço onde o processo de colonização está instituindo novas relações sociais ou redefinindo antigas; a noção de fronteira não pressupõe a inexistência de formas prévias de articulação desses espaços à sociedade, nem um processo de ocupação contínuo, em bloco, como sugerido pela expressão norte-americana "fronteira em movimento". Pressupõe uma estrutura social dinâmica e relativamente "em aberto", associada à ocorrência de movimentos de ocupação ou reocupação de terras. (BECKER, 1988, p. 65).

Musumeci enxerga a fronteira não como um movimento linear, mas dinâmico, "em aberto", como processo de redefinição de relações sociais ou de instalação de novas, onde se ocupam ou se reocupam terras que não necessariamente estavam "cheias de vazios", como sugere a ideia dos "vazios demográficos" apontada por Porto Gonçalves e Quental (2013). Também a partir de uma leitura não maniqueísta da expansão das fronteiras - na qual as populações camponesas são sinônimo do atraso e indisposição para o novo, ao passo que os projetos capitalistas representam progresso, avanço e desenvolvimento na fronteira - somos contempladas pela visão de Martins (1997), para quem a fronteira não é o local de mera oposição de mundos (velho versus novo), e sim o local onde a situação de conflito social é iminente.

Isto implica dizer que na fronteira coabitam vários "mundos" (aqui entendidos como distintas práticas e lógicas de ocupação da terra e do território) que se chocam, resultando em conflitos. Para Martins, a fronteira é "essencialmente o lugar da alteridade" (MARTINS, 1997, p. 150). Possui, por sua vez, uma realidade singular, do encontro e da 
Quando os sonhos de desenvolvimento produzem monstros: a violência como parte da estratégia de modernização no campo brasileiro

descoberta do outro, mas ao mesmo tempo um local de desencontro de distintas concepções de vida, visões de mundo e temporalidades históricas. Pelo seu contato, induz a tensões e conflitos na aproximação dos diferentes, os quais "estão juntos na complexidade de um tempo histórico composto pela mediação do capital, que junta sem destruir inteiramente essa diversidade de situações” (MARTINS, 1997, p.159).

A partir dessa disparidade, Bertha Becker (1988) aponta que, desde sempre, os movimentos de ocupação e colonização demonstram que a fronteira é o local de reprodução camponesa, seja por autonomia ou por submissão, local onde permanecem formas não capitalistas e capitalistas na agricultura mesmo diante do intenso crescimento urbano-industrial, pois a reprodução não capitalista é funcional ao capital. Há, segundo a autora, um confronto entre pelo menos dois modos opostos de pensar/usar/ocupar a terra na fronteira: um modo que privilegia os direitos de posse, o trabalho, a cultura e os valores imateriais, ou seja, o território de uso e costumes; e outro, que tem como foco a propriedade privada e o mercado. Por esta razão é que, para a autora, as fronteiras são espaços em incorporação ao espaço global, onde são sediados tanto projetos de colonização e desenvolvimento subsidiados pelo Estado, como também unidades produtivas vinculadas às várias frações do capital, com financiamento não só do capital comercial usurário, como do capital bancário e outra frações (BECKER, 1988).

Até aqui é importante destacar que não compactuamos com o sentido da fronteira como um momento ou espaço inaugural de um "mundo novo" e "ilimitado" de bens e recursos, apenas à espera para ser explorado. Em sua concepção geral e difundida a partir de projetos de ocupação territorial, é a partir desta linha de raciocínio que se definem os percursos para o desenvolvimento de uma nação, impondo-se não só novas trajetórias e ciclos econômicos a partir da expansão sobre novas terras, como também uma novidade em termos civilizatórios, novidade esta que é aqui questionada em termos de seus proveitos. As fronteiras, deste ponto de vista são caracterizadas como "fundos territoriais" ou "sertões", reservas de espaço ainda não plenamente incorporadas ao capital, sobre as quais se desenrolam movimentos de expansão e integração, conforme indica Moraes (2011),

Assim, via de regra, a expansão de fronteiras se dá no sentido de incorporar áreas e regiões com potenciais econômicos, das quais se pode extrair mais-valia e proceder na acumulação por parte dos agentes capitalistas, quaisquer que sejam eles: latifundiários, 
Quando os sonhos de desenvolvimento produzem monstros: a violência como parte da estratégia de modernização no campo brasileiro

empresas privadas, especuladores ou bancos, por exemplo, que se utilizam de métodos mais usuais (legais ou ilegais), como a compra e grilagem de terras, mas que, atualmente, também acionam mecanismos de financeirização e internacionalização de terras e da natureza (SAUER, 2010; CASTRO, HERSHAW, SAUER, 2017). Mais do que compreender a fronteira como uma franja territorial intocada a ser ocupada (avanço "para frente" da fronteira territorial, como foi o caso da ocupação, no século XX, do CentroOeste e da Amazônia brasileira), entendemos a expansão da fronteira como um novo nicho de mercado, dinamizando terras já descobertas e estocadas, porém, não mercantilizadas (expansão "para dentro" das possibilidades de esgarçamento da fronteira capitalista, como é o caso de unidades de conservação e terras indígenas), o que evidencia mecanismos atualizados de controle sobre a terra e a natureza.

Por esta razão, ressaltamos que a fronteira funciona como uma zona ou processo conflituoso de ocupação territorial, no qual se manifestam e combinam formas diversas da violência. Portanto, a pergunta que fazemos é: sobre qual novidade falamos se nas fronteiras do desenvolvimento não se realizam sonhos, mas pesadelos? Que sonhos de desenvolvimento são esses?

\section{O "desenvolvimento"}

A incorporação dos fundos territoriais a uma dinâmica de uso/exploração intensiva, sustentada sob a égide de um discurso de promoção do tão desejado “desenvolvimento" segue uma lógica. De acordo com Moraes (2002; 2011), nas periferias do capitalismo a dominação se objetiva sem a alocação de grandes massas de capital no espaço, o que resulta num padrão espoliativo do ponto de vista geográfico, ao mesmo tempo em que gera empobrecimento local. A baixa alocação de recursos, no entanto, não implica em baixos níveis de exploração da natureza, dado que, pelo contrário, ocorre uma verdadeira "drenagem" da riqueza localizada nos fundos territoriais. Segundo Moraes (2011), as áreas periféricas foram, desde sempre, fornecedoras de produtos naturais, tendo como base o extrativismo vegetal, a exploração mineral, a agricultura ou a pecuária.

Ocorre que ao longo desse movimento, a expansão capitalista atua coordenando formas capitalistas com formas pré-capitalistas ou não capitalistas. Desta maneira, subordina todas as formas de produção defrontadas em seu avanço territorial, o que não 
Quando os sonhos de desenvolvimento produzem monstros: a violência como parte da estratégia de modernização no campo brasileiro

implica em destruí-las de imediato, mas em incorporá-las, adaptando e convivendo com estruturas estranhas, associando características opostas, num movimento contraditório, combinado e desigual. Sendo este o padrão de acumulação característico de suas periferias, nelas convivem formas de produção tradicionais com formas de produção mais recente, conformando um mosaico geográfico, econômico e social de grande variedade interna (MORAES, 2011).

Periodicamente, ocorrem ondas sucessivas de "modernização" nas periferias do capitalismo, como forma de ajustes constantes oriundos das demandas dos países centrais que, de modo cíclico, readequam as sub-economias às relações dominantes e incorporam determinadas áreas geográficas ao cerco econômico. Assim sendo, "nos espaços periféricos, as formas de valorização do espaço introduzidas pela subordinação dos lugares à lógica e à dinâmica do capitalismo não reproduzem especificamente o 'modelo' de valorização capitalista do espaço" (MORAES, 2002, p. 20). Este fato acarreta numa particularidade de acumulação originária nas periferias e impõe um desenvolvimento geográfico desigual e violento.

No encalço das novas fronteiras de acumulação do capitalismo periférico o que fica demonstrado é que há novos-velhos colonialismos na periferia, periferia esta que durante o período colonial tinha como função prioritária o fornecimento de produtos primários ao mercado europeu. Entretanto, no período pós-colonial, apesar de algumas regiões terem sido incorporadas em projetos supostamente mais "modernos", ou projetos de "desenvolvimento", tais como infraestruturas diversas (estradas, hidrelétricas...), indústrias e capitais de outra feição, inclusive financeiros, na periferia do capital há persistência na exploração desmedida da natureza. Ou seja, ocorre um neocolonialismo, no qual permanecem coexistindo formas arcaicas e modernas, formas tidas como superadas concomitantemente a formas inovadoras de produzir. Nas palavras de Moraes (2011) há um "móvel extrativista" em atuação, no qual funções distintas se sobrepõem ao longo da história num mesmo lugar, articulando o capital primário com novas frações do capital.

Atualmente, a articulação entre capital primário e novas frações do capital tem como uma de suas faces as políticas de desmantelamento das normas legislativas e jurídicas que garantem a determinados grupos os direitos sobre o uso das suas terras e territórios. Isto se dá especialmente a partir de agroestratégias ruralistas (ALMEIDA, 
Quando os sonhos de desenvolvimento produzem monstros: a violência como parte da estratégia de modernização no campo brasileiro

2010), que têm como finalidade incorporar de forma acelerada novas extensões de terra ao mercado de commodities, gerando uma série de tensões e disputas em torno da demarcação de territórios tradicionais, ou de áreas de conservação e preservação, como Unidades de Conservação de uso integral e sustentável, que são vistas como obstáculos à expansão das fronteiras de acumulação ruralistas (GUEDES, 2013; PEREIRA, 2018).

Neste cenário, são pautados alguns mecanismos legislativos essenciais para a expansão das fronteiras capitalistas, tais como os citados por Eduardo Barcelos (2017, no prelo) e Carolina Pereira (2018): o desmonte e a simplificação do rito do licenciamento ambiental (PLS no 654/2015, PLS n 602/2015, PEC 65/2012, PL n 3.729/2004), a liberação de mineração em terras indígenas (PL 1610/1996), a transferência da competência da demarcação das terras indígenas e quilombolas do poder executivo para o legislativo (PEC 215/2000), ou a facilitação da posse indireta de terras indígenas a produtores rurais na forma de concessão (PEC 237/2013). Paralelamente, observa-se o desmonte e o enfraquecimento de órgãos de caráter ambiental, como o IBAMA (Instituto Brasileiro do Meio Ambiente e dos Recursos Naturais Renováveis) e o ICMbio (Instituto Chico Mendes de Conservação da Biodiversidade), bem como daqueles responsáveis por executar a reforma agrária ou de atuação em questões indígenas, como o INCRA (Instituto Nacional de Colonização e Reforma Agrária) e a FUNAI (Fundação Nacional do Índio).

Embora não sejam novidades no que diz respeito ao mercado de terras, os mecanismos de apropriação da natureza, das terras e territórios ainda "disponíveis" para oo mercado também têm se intensificado através da internacionalização e financeirização do capital, com rebatimentos principalmente no espaço agrário. As formas de acumulação vêm ganhando novas roupagens e um dos elementos mais comuns, tanto na Amazônia quanto no Cerrado, é a estrangeirização das terras ("land grabbing”), tratando as fronteiras econômicas no espaço agrário como uma questão também geopolítica (CASTRO, HERSHAW, SAUER, 2017).

$\mathrm{Na}$ corrida do capital pela aquisição de áreas, o termo "land grabbing" foi traduzido como "estrangeirização de terras". No entanto, devemos entender que faz parte de processos mais amplos de internacionalização, pois não se reduz a operações de compra ou arrendamento de glebas por estrangeiros. São processos de apropriação por uma série de iniciativas e mecanismos, que vão de investimentos (compra, leasing, arrendamentos, etc.) por estrangeiros a mudanças legais que rompem as fronteiras nacionais. É fundamental entender 


\begin{abstract}
o "land grabbing" como "apropriação do controle" (MEHTA, VELDWISH e FRANCO, 2012, p. 195) sobre terras e recursos da terra, extraindo e alienando "recursos para propósitos externos (nacional ou internacional)" (BORRAS JÚNIOR et al., 2012, p. 850). Essas transações e mecanismos titularizam direitos em favor de pessoas (físicas e/ou jurídicas) estrangeiras ou abrem possibilidades (flexibilização de leis e normas, criação de mecanismos de 'preservação', etc.) de apropriação da terra e dos frutos da terra (ou da renda fundiária) que transcendem ou rompem as barreiras nacionais. (CASTRO, HERSHAW; SAUER, 2017, p. 75-76).
\end{abstract}

Sauer (2010), mencionando Arruda (2006), aponta que desde meados dos anos 2000, notícias veiculadas na grande imprensa demonstram que vem aumentando o interesse de pessoas e empresas estrangeiras por terras brasileiras, associadas, principalmente, aos projetos de produção de biocombustível (embora o ramo represente apenas parte dos negócios de terras), atraindo até mesmo fundos de investimentos estrangeiros. Sérgio Sauer (2010) aponta também que, de acordo com estudos do Banco Mundial, o crescimento da produção agrícola e da demanda por compras de terra se concentra na expansão de apenas 8 commodities agrícolas: milho, dendê (óleo), arroz, canola, soja, girassol, cana de açúcar e floresta plantada (pinus e eucalipto, por exemplo). O processo de "commoditização" da agricultura fundiu formas antigas de exploração da terra (plantations) com formas contemporâneas, unindo "os sistemas agropecuário com os sistemas industrial, mercantil, financeiro e tecnológico, formando o agronegócio" (CASTRO, HERSHAW, SAUER, 2017, p. 80). A essa combinação, soma-se também a fusão entre capital nacional e internacional, favorecendo as inserções dos negócios de terras nos mercados globais.

Portanto, não nos parece uma mera coincidência que a ampliação de interesses em terras brasileiras esteja associada ao desmonte legislativo que propicia o avanço da fronteira capitalista para terras indígenas, quilombolas, áreas de preservação ambiental e outras que são tratadas pelo mercado como "fundos" ou "estoques" de valor. Não por acaso, tais avanços e aquisições ocorrem em biomas estratégicos, como o Cerrado e a Amazônia, encarecendo terras, dificultando a realização de políticas públicas e a desapropriação para fins de reforma agrária. Na prática, isso tem representado a expropriação de comunidades do campo (CASTRO, HERSHAW, SAUER, 2017).

No que diz respeito ao avanço no bioma do Cerrado, hoje, um dos projetos mais ousados de expansão do agronegócio, representativo do processo de estrangeirização e financeirização de terras é o MATOPIBA, projeto que abarca cerca de 73 milhões de 

a violência como parte da estratégia de modernização no campo brasileiro

hectares em 337 municípios. Seu nome agrega as siglas dos estados de abrangência do projeto: Maranhão (MA), Tocantins (TO), Piauí (PI) e Bahia (BA). Em 6 de maio de 2015, através do Decreto $n^{\circ}$ 8447, foi criado o Plano de Desenvolvimento Agropecuário do MATOPIBA. Nesse plano, foi proposta a coordenação de políticas públicas de desenvolvimento econômico "sustentável" das atividades agropecuárias. Conforme também indicam Castro, Hershaw e Sauer (2017), no MATOPIBA a tônica é a expansão dos monocultivos de eucalipto, cana, soja, produção de álcool e outros biocombustíveis, além da criação pecuária. Embora bastante pobre, a região do projeto teve um crescimento de sua área plantada em $400 \%$ nos últimos vinte anos. "Esses dados o posicionam como uma "frente de expansão capitalista e fronteira de estrangeirização da terra" (CASTRO, HERSHAW, SAUER, 2017, p. 89).

\begin{abstract}
A região do MATOPIBA está passando por um processo de transformação da terra em um bem financeiro desmaterializado em decorrência do aumento do poder e influência do sistema financeiro mundial, e de mudanças em suas formas de operar - este processo é conhecido como 'financeirização'. Uma das faces deste processo é o fato de que os agentes financeiros (como bancos, empresas de corretagem, seguradoras, fundos de pensão, fundos de investimento, agências de investimento e fundos de capital de risco), estão, cada vez mais, vendo a terra como uma boa opção de investimento. Esses agentes financeiros canalizam seus fundos para a compra de terras e para atividades relativas ao uso da terra, de forma a diversificar seus investimentos, aumentar os lucros e diminuir os riscos. Os planos e fundos de pensão estão entre os principais agentes envolvidos neste contexto de financeirização e apropriação de terras. (FIAN INTERNACIONAL, RSJDH, CPT, 2017, p.5).
\end{abstract}

Becker confirma que mesmo que a valorização da natureza hoje seja condicionada por tecnologias, "a virtualidade dos fluxos e redes financeiras e informacionais não significam a dissolução do espaço geográfico e do valor estratégico da riqueza in situ" (2007, p.34). Ou seja: ainda que os negócios sejam mais intensamente realizados virtualmente, o espólio continua sendo local. Neste sentido, uma série de segmentos tradicionais que residem e subsistem no Cerrado e nas áreas onde se implantou o MATOPIBA (indígenas, quilombolas, quebradeiras de coco babaçu, etc.) sofrem os prejuízos da especulação financeira sobre a terra, assim como o próprio bioma, a partir da expropriação da terra e da exploração excessiva, respectivamente.

Neste ínterim, é categórico reconhecer que esse processo não incide sobre fronteiras vazias ou espaços desocupados por "gente", mas desocupados pelo capital e pelo mercado. Assim, a tendência é integrar espaços ainda pouco vinculados e pouco 
Quando os sonhos de desenvolvimento produzem monstros: a violência como parte da estratégia de modernização no campo brasileiro

produtivos para o mercado, realizando a transformação de fundos territoriais em ativos territoriais de produção intensiva para o agronegócio ou a especulação da terra, que se tornou um "bem financeiro desmaterializado" (FIAN INTERNACIONAL, RSJDH, CPT, 2017). Inevitavelmente, tais dinâmicas de ocupação implicam em conflitos fundiários e territoriais que, por sua vez, refletem em acirramento da violência, conforme discutiremos no próximo tópico.

É curioso notar que os processos de estrangeirização de terras e do avanço do agronegócio na fronteira agrícola, embora sempre associados a um imaginário da modernização do campo, se apropriam de táticas espúrias e ilegais, demonstrando a face perversa da modernidade/colonialidade (QUIJANO, 2005; MIGNOLO, 2005) de tais práticas. A começar pelos próprios procedimentos utilizados para a aquisição de terras: além dos processos formais de compra e venda de terras, a estrangeirização adquire terras provenientes de processos de grilagem, nas quais grileiros forjam e falsificam escrituras e títulos definitivos de compra de terras devolutas, ou seja, terras públicas. Portanto, tratase de transações criminosas de aquisição de terras e do bem comum (CASTRO, HERSHAW; SAUER, 2017).

Dentre os agentes investidores de terras na região do MATOPIBA, encontramse fundos de pensão norte-americanos, como é o caso da TIAA-CREF, que faz parte de uma joint venture com a Cosan ${ }^{3}$. Conforme relatório indicado por Castro, Hershaw e Sauer (2017), elaborado pela Rede Social de Justiça e Direitos Humanos do Brasil, pela GRAIN e por outras ONGs, ambos agentes têm adquirido fazendas na região controladas pelo latifundiário Euclides de Carli, um dos mais poderosos grileiros do Maranhão e Piauí. Há uma investigação em curso no Poder Judiciário do Piauí a respeito desses vínculos, que demonstram que o fundo internacional, juntamente com a empresa brasileira, estaria atuando de maneira ilícita na aquisição de terras, emitindo títulos falsos na região, o que demonstra ligações entre a grilagem de terras e o capital internacional. Sobre Euclides de Carli, transcrevemos alguns trechos de matéria publicada pela ONG Repórter Brasil em 2 de setembro de 2018:

Carli é definido como "o senhor das terras" pelo juiz Heliomar Rios, da vara agrária de Bom Jesus, no Piauí. O juiz estima que ele tenha abocanhado, por

\footnotetext{
3 A Cosan é uma das maiores empresas do Brasil, com investimentos em setores estratégicos como agronegócio, distribuição de combustíveis e de gás natural, lubrificantes e logística. Fonte: http://www.cosan.com.br/pt-br/cosan/quem-somos.
} 
meio de fraudes e falsificações, território equivalente a duas cidades de São Paulo (300 mil hectares).

Carli também é acusado pelas famílias das vítimas e por pequenos produtores rurais de ter ameaçado e mandado matar aqueles que se opuseram a ele no processo de apropriação de terras. Apesar das suspeitas de crimes que rondam o latifundiário, Carli se gaba de nunca ter sido condenado por grilagem.

Se por um lado Carli é acusado de roubar terras, por outro ele é apontado como um dos responsáveis por modernizar o Nordeste ao abrir caminho para que grandes empresas produtoras de soja e algodão entrassem no Sul do Maranhão e Sudoeste do Piauí. "É a nova fronteira agrícola que se abre e ninguém segurará este progresso", profetizou Carli em uma carta enviada a um missionário há 24 anos.

O latifundiário é definido pelo jornal norte-americano [New York Times] como "empresário nebuloso" ("shadowy", em inglês), além de "um especulador de terra acusado de empregar pistoleiros para roubar, por meio da força, terras dos agricultores pobres".

"Euclides de Carli atua com o aval do estado. Extorque terras da região, além de usar violência física e psicológica. Usa métodos lícitos e ilícitos. Desde oferecer grana abaixo dos valores de mercado até o uso de segurança armada para amedrontar famílias".

"Uma das estratégias do grupo chefiado por Carli, segundo a investigação contra ele, seria justamente essa: desarticular, ameaçar e aliciar famílias que moram nas terras de seu interesse [...].algumas famílias receberam dinheiro para deixarem suas terras ou para ficarem divididas e brigarem entre si (REPÓRTER BRASIL, 2018 - grifo nosso).

Nosso objetivo aqui não é o de aprofundar na investigação sobre o caráter das transações envolvendo a apropriação e a grilagem de terras, mas de investigar os laços entre o capital internacional e nacional, a estrangeirização de terras, as áreas de expansão de fronteiras agrícolas e os casos de violência no campo, apontando para a multiescalaridade entre processos globais e locais, do capital financeiro e transnacional, até os impactos sobre a escala do corpo. Tais vínculos demonstram o casamento entre práticas modernas e coloniais, entre legalidade e ilegalidade, entre desenvolvimento e violência na expansão dos investimentos no campo, bem como os rebatimentos que tais investimentos trazem no avanço da fronteira capitalista sobre áreas estratégicas, como é o caso da Amazônia Legal e do Cerrado. As consequências são evidenciadas na concentração de terras ("o senhor das terras"), no roubo/rapinagem de terras de pequenos agricultores, na ameaça, no assassinato com o uso de pistoleiros, no uso de violências físicas e psicológicas e outros tantos mecanismos violentos que afetam diretamente diferentes segmentos do campo, que subsistem em terras e territórios que são de interesse 
Quando os sonhos de desenvolvimento produzem monstros: a violência como parte da estratégia de modernização no campo brasileiro

do mercado. Seriam esses os custos da expansão da fronteira, em nome do progresso, da modernização e do desenvolvimento?

\section{A violência (sem aspas)}

Até aqui, foi possível constatar as contradições presentes no processo de ampliação das fronteiras do capitalismo no espaço agrário. A "modernização do nordeste", que o grileiro e latifundiário Euclides de Carli supõe realizar abrindo caminhos [fronteiras] para que empresas de soja e algodão se instalem na região do Maranhão e do Piauí são elementos que evidenciam o fato de que a violência não é ponto fora da curva, mas parte intrínseca do capitalismo, desdobrando-se através de uma série de mecanismos, que incluem desde pressões psicológicas, chantagens na negociação de terras e até mesmo o cometimento de crimes e assassinatos. Destacamos, portanto, que há uma relação umbilical entre o deslocamento espacial do capitalismo na fronteira e a distribuição desigual das práticas de violência. Nas fronteiras do capitalismo, a violência é veículo e mecanismo de acumulação através da ocupação do espaço, produzindo uma distribuição regional desigual de práticas necroeconômicas e necropolíticas.

Para Joe Foweraker (1981), estes elementos são sintomáticos da reprodução do capitalismo periférico, no qual o desenvolvimento reforça os modos subcapitalistas para permitir a integração ao mercado mundial. Assim, o subcapitalismo reproduz o capitalismo, articulando modos de expansão arcaicos e feudais com modos de circulação e produção modernos. O processo de expansão da fronteira estende a amplitude da acumulação primitiva e estabelece o ambiente subcapitalista: "Qualquer processo de acumulação requer a captação de um excedente e a violência serve a essa finalidade no processo de acumulação primitiva" (FOWERAKER, 1981, p.222). A fronteira é marcada por atividade predatória dominante e é onde se instalam extrativismos de natureza e de humanidade de maneira intensiva e agressiva.

A coerção e a violência, assim, evidenciam-se como estratégias constituintes da preservação das condições gerais de acumulação. A fronteira aparece como elo final das relações centro-periferia, tanto em termos geográficos quanto em termos funcionais, e é nela que as contradições vão se descarregar violentamente. Junto com a lei e a burocracia, a violência forma uma tríade poderosa, marcando o teor e as mediações da luta na fronteira. Por sua vez, lei, burocracia e violência estão conectadas aos aparelhos legais e 
Quando os sonhos de desenvolvimento produzem monstros: a violência como parte da estratégia de modernização no campo brasileiro

políticos do estado e aos aparelhos privados, que se complementam entre si (FOWERAKER, 1981) - conforme indicado no quadro 1.

Quadro 1: Os agentes da violência, da lei e da burocracia

\begin{tabular}{|c|c|}
\hline AGENTES PÚBLICOS & AGENTES PRIVADOS \\
\hline \multirow{3}{*}{$\begin{array}{l}\text { Políticos locais e nacionais (poderes legislativos e } \\
\text { executivos municipais, estaduais e federais) }\end{array}$} & Fazendeiros \\
\hline & Latifundiários \\
\hline & Advogados \\
\hline Juízes & $\begin{array}{l}\text { Empresários (ramo energético, mineral, } \\
\text { agronegócio, biocombustíveis e outros) }\end{array}$ \\
\hline \multirow[t]{2}{*}{ Forças armadas } & Investidores (nacionais e internacionais) \\
\hline & Fundos de pensão \\
\hline \multirow{3}{*}{$\begin{array}{l}\text { Polícias (Civil, Militar, Federal, Ambiental, Forças } \\
\text { especiais de operação) }\end{array}$} & Grileiros \\
\hline & Agências imobiliárias rurais \\
\hline & Jagunços \\
\hline $\begin{array}{l}\text { Funcionários e técnicos de órgãos do estado } \\
\text { (secretarias, ministérios etc.) }\end{array}$ & Pistoleiros \\
\hline Agentes de desenvolvimento & Milícias privadas e empresas de segurança \\
\hline $\begin{array}{l}\text { Funcionários e técnicos do INCRA e dos institutos } \\
\text { estaduais de terras }\end{array}$ & \\
\hline
\end{tabular}

Fonte: Foweraker, 1981.

Org.: Elaboração própria, 2019.

Com superioridade econômica e política, agentes privados afirmam direitos (que sequer existem) sobre a terra e coadunam com práticas que promovem expropriação e expulsão de pequenos agricultores e comunidades tradicionais. Como para estes agentes a terra é meramente fator de negócios produtivos, financeiros e especulativos e para outros (agricultores, quilombolas, indígenas) é fator primordial de sobrevivência, num quadro de oposições, o processo econômico de ocupação das terras e territórios transforma-se numa luta política marcada pela violência (FOWERAKER, 1981).

Um caso que evidencia essa articulação entre estado e interesses privados pode ser retirado do relatório produzido pela FIAN Internacional, em Parceria com a Rede Social de Justiça e Direitos Humanos do Brasil e a Comissão Pastoral da Terra (CPT), de 2017, que teve como missão analisar impactos ambientais e direitos humanos causados pela expansão do agronegócio e da especulação na região do MATOPIBA, a partir de visitas às comunidades incluídas no perímetro do projeto, onde moradores relataram ameaças:

Adaildo José da Silva, morador da comunidade Morro D’água, relatou à missão que um advogado tentava expulsá-lo de suas terras há anos por meio 


\begin{abstract}
de ameaças, documentos falsos e até mesmo violência. No dia 19 de setembro de 2017, Valdimar Delfino dos Santos, que é funcionário do advogado em questão, agrediu fisicamente o Sr. Silva e o ameaçou de morte. $O$ Sr. Silva registrou queixa na polícia em diversas ocasiões, mas sem resultado. Em fevereiro de 2018, homens armados entraram mais uma vez na comunidade procurando por Adaildo José da Silva, que felizmente não estava em casa. As ameaças contra ele e sua família continuam. (FIAN INTERNACIONAL, RSJDH, CPT, 2017, p.59 - grifo nosso).
\end{abstract}

Os destaques no trecho demonstram a falta de proteção e amparo policial e jurídico a que estão expostos os moradores de comunidades que sofrem com grilagem e especulação de terras. O estado, representado por estes entes, deixa alguns à própria sorte; resta-lhes somente a organização em movimentos sociais, frequentemente perseguidos e criminalizados, ou contar com o parco amparo de algumas organizações não governamentais, de organizações de setores progressistas dentro da Igreja Católica, como é o caso da Comissão Pastoral da Terra (CPT), Confederação Nacional dos Bispos do Brasil (CNBB), do Conselho Indigenista Missionário (CIMI), ou de órgãos do estado, como a Defensoria Pública ou Ministério Público. Entretanto, de maneira geral, os camponeses e populações atingidas atuam sozinhos, individualmente, estando à mercê de toda sorte de violência e até mesmo da morte. Quando muito, as mortes e violências são publicitadas, porque dificilmente são registradas ou suas investigações levadas adiante, como se demonstrou na passagem destacada anteriormente.

Com a predominância de uma lógica industrial-moderna-tecnológica da agricultura contemporânea, a mobilidade "para frente"- como característica habitual do camponês, segundo aponta Candido (2010) - é cerceada. Quando se vê encurralado em sua própria comunidade, ao invés de mover-se para a próxima fronteira em aberto, o trabalhador rural desloca-se para as cidades à procura de novos meios de vida, impondolhe uma transição de maior submissão e dependência do mercado de trabalho e perda da capacidade de subsistência o que, na prática, implica na descaracterização do trabalho costumeiro e da vida rural. Para os expropriados, a expulsão da terra é cada vez mais sinônimo de inclusão periférica no mercado: conseguir um subemprego, residir na periferia de grandes cidades, tornar-se assalariado ou meramente um prestador de serviço autônomo. A descaracterização de seu modo de viver é frequentemente abrupta e indesejada, o que não deixa de ser também uma das faces da violência no campo, pois não há nada mais impactante do que perder o controle sobre o seu chão, sobre seu próprio ofício e sobre o(s) seu(s) próprio(s) modos de "saber-fazer". 
Quando os sonhos de desenvolvimento produzem monstros: a violência como parte da estratégia de modernização no campo brasileiro

Para traduzir a discussão sobre violência em alguns dados, o Relatório de Conflitos no Campo no Brasil de 2017, produzido pela Comissão Pastoral da Terra (CPT, 2017) demonstra que todos os 26 estados da federação (com exceção do Distrito Federal), registraram algum conflito por terra em 2017, conforme indicado no gráfico 1 . No ano anterior, 2016, foram 635 conflitos por terra e 109 conflitos por água somente na região do MATOPIBA, superando os números dos últimos 20 anos.

Gráfico 1: Conflitos por terras nas unidades da federação (Brasil), em 2017

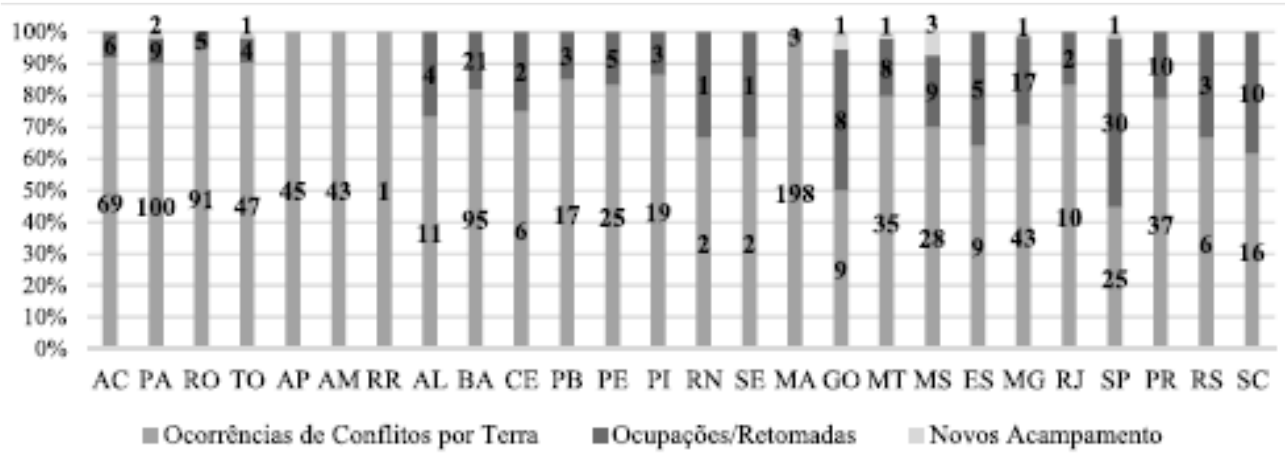

Fonte: CPT, 2018.

Org.: COSME, 2018.

O gráfico acima reafirma a concentração de conflitos nas regiões Norte e Nordeste do Brasil, especialmente em estados cuja fronteira de grandes projetos (mineração e energéticos, por exemplo) e de negócios com a terra (agronegócio e estrangeirização de terras) está em expansão. Não por acaso, os maiores registros de violência se encontram justamente em estados da Amazônia Legal ou do MATOPIBA, duas fronteiras crescentes de atração do capital nacional e internacional.

O estado do Maranhão é de longe, aquele onde a classe dos proprietários capitalistas da terra mais atuou, ocorrendo 17,21\% (201) do total geral de 1.168 Conflitos por Terra, com maioria absoluta das ocorrências (198) e, apenas, 3 ocupações/retomadas; em seguida vem a Bahia, com 9,93\% (116, sendo 95 ocorrências e 21 ocupações/retomadas); o Pará, com 9,5\% (111, sendo 100 ocorrências, 9 ocupações/retomadas e 2 acampamentos novos) e Rondônia, com $8,22 \%$ (96, sendo 91 ocorrências e 5 ocupações/retomadas). Esses quatros estados concentraram 44,86\% (524) do total geral dos Conflitos por Terra (...). Notem que apenas o Maranhão não sofreu com as chacinas, portanto, além dos massacres sofridos, Bahia, Pará e Rondônia, conviveram com outros tipos de violência protagonizada pelos conhecidos ruralistas do agronegócio. (CPT, 2017, p. 103 - grifo nosso). 
Quando os sonhos de desenvolvimento produzem monstros: a violência como parte da estratégia de modernização no campo brasileiro

Conforme assinalado, uma das características da ofensiva no campo a partir de 2017 foi a generalização dos assassinatos. Se antes os homicídios eram mais seletivos em seus alvos, priorizando lideranças do campo, naquele ano evidenciou-se o resgate da prática de chacinas, massacres ou tentativas de massacres coletivos (CPT, 2017). Não por acaso, tais acontecimentos se deram justamente em 4 dos estados onde há maior evidência de violência no campo, de acordo com levantamento da CPT: Maranhão, Bahia, Pará e Rondônia. Amazonas e Mato Grosso, apesar de não serem os mais violentos no campo em 2017, apresentam considerável registro de conflitos (43 registrados em cada um), e também estão nas áreas da Amazônia Legal.

Quadro 2: Massacres e tentativas de massacre no campo (2017)

\begin{tabular}{|c|c|c|}
\hline LOCAL DAS CHACINAS & QUANDO & VÍTIMAS \\
\hline $\begin{array}{l}\text { MATO GROSSO (MA) } \\
\text { Colniza - Assentamento } \\
\text { Taquaruçu do Norte }\end{array}$ & Abril & $\begin{array}{l}9 \text { posseiros assentados assassinados por pistoleiros a } \\
\text { mando de madeireiros }\end{array}$ \\
\hline $\begin{array}{l}\text { MARANHÃO (MA) } \\
\text { Viana - Indígenas Gamela }\end{array}$ & Abril & $\begin{array}{l}22 \text { indígenas feridos, sendo } 5 \text { baleados, } 2 \text { amputados a } \\
\text { mando de fazendeiros devido à disputas territoriais }\end{array}$ \\
\hline $\begin{array}{l}\text { RONDÔNIA (RO) } \\
\text { Vilhena }\end{array}$ & Maio & 3 trabalhadores rurais assassinados \\
\hline $\begin{array}{l}\text { PARÁ (PA) } \\
\text { Pau D'Arco }\end{array}$ & Maio & $\begin{array}{l}10 \text { camponeses assassinados pela Polícia Civil e Militar } \\
\text { do PA }\end{array}$ \\
\hline $\begin{array}{l}\text { BAHIA (BA) } \\
\text { Lençóis - Comunidade } \\
\text { quilombola de Iúna - }\end{array}$ & Julho & 6 quilombolas assassinados \\
\hline $\begin{array}{l}\text { AMAZONAS (AM) } \\
\text { Canutama }\end{array}$ & Dezembro & $\begin{array}{l}3 \text { camponeses ( } 2 \text { homens e } 1 \text { mulher), lideranças do } \\
\text { MST }\end{array}$ \\
\hline & & TOTAL: 31 assassinados e 22 feridos \\
\hline
\end{tabular}

A quem interessam todas estas mortes? Como se pode observar, "os camponeses da fronteira experimentam a violência não ocasional, persistentemente" (FOWERAKER, 1981, p.48). Não é mero acaso que tais corpos sejam abatidos justamente em áreas de expansão da fronteira capitalista, em áreas da Amazônia Legal e do MATOPIBA. Notase que os corpos eliminados não estão em qualquer lugar e também não são quaisquer corpos. Não que a morte de algum indivíduo possa ser delegada a um plano "qualquer", 
Quando os sonhos de desenvolvimento produzem monstros: a violência como parte da estratégia de modernização no campo brasileiro

mas o que gostaríamos de ressaltar é que há um direcionamento da violência para com determinados sujeitos, especialmente camponeses, povos e comunidades tradicionais (quilombolas e indígenas), tais como lideranças políticas que geralmente estão imbuídas em lutas diversas pela terra/território. Porém, os dados demonstram que o simples fato de ser um agricultor ou indígena ou quilombola e de fazer valer práticas outras de usufruto e manutenção de seus territórios já os relega ao plano dos matáveis, daqueles cuja improdutividade e inutilidade para o sistema fora testada e atestada pelo capital espoliador ${ }^{4}$.

Eliminam-se, pois, como obstáculos, como entraves para projetos mais ambiciosos, coordenados pelo grande latifúndio, pelo empresariado dos ramos energéticos, mineral e outros, pelos investidores nacionais e internacionais, pelos fundos de pensão, pelas agências imobiliárias, ou seja, pelos agentes do "desenvolvimento" que, atrelados aos agentes jurídicos (advogados, poder judiciário) e aos agentes "acima" da lei (grileiros, jagunços, milícias), dilaceram os territórios com a mesma intensidade com que dilaceram corpos.

Tais elementos compõem a Geografia da violência no campo no Brasil, na qual se evidenciam conflitividades regionais específicas que mesclam, como padrão, acumulação primitiva permanente, práticas de colonialidade interna e estado de exceção. Nesta tríade, o corpo aparece como desígnio final da escalaridade da violência, que "catalisa tanto a perpetuação do ciclo de acumulação como a reprodução da clássica concentração da propriedade no campo" (FOWERAKER, 1981, p.227).

Neste sentido, os sonhos de desenvolvimento com a ampliação de projetos na fronteira produzem monstros, monstros estes que são traduzidos como mortes e assassinatos de corpos específicos e de aniquilamento de suas práticas e memórias.

\section{Para encerrar: como despertar da interminável noite? ${ }^{5}$}

\footnotetext{
${ }^{4}$ Incentivam a violência no campo discursos como estes: "Quilombola não serve nem pra procriar"; "Esses vagabundos vão ter que trabalhar"; "Não vai ter um centímetro demarcado para reserva indígena ou para quilombola."; "Vamos dar fuzil e armas a todos os fazendeiros". (Fonte: O GLOBO, 2018; SURVIVAL, 2019).

${ }^{5}$ Parafraseando acidentalmente Achille Mbembe, com quem, após a escrita deste texto, tive contato com sua obra intitulada "Sair da grande noite: Ensaio sobre a África descolonizada" (2019).
} 
Apropriação, expulsão, força, roubo, violência física, violência psicológica, aliciamento, desarticulação, ameaça, extorsão, perseguição, assassinato, amputação, fraude, falsificação, grilagem, pistolagem, medo... Estas expressões, mencionadas em algum momento ao longo desse texto, e tantas outras aqui não contidas, indicam ações e mecanismos comumente acionados na expansão de projetos de desenvolvimento no espaço agrário, demonstrando que há uma Geografia da Violência no campo brasileiro. Exercida conjuntamente com agentes públicos e privados que estão tanto dentro da lei visto que a confusão legal é parte da estratégia - quanto acima dela - dado que a ação ilegal também cumpre o seu papel - desencadeiam-se processos de expropriação de trabalhadores rurais camponeses, povos e comunidades tradicionais em áreas de fronteira para o capital, reservas de valor ainda subexploradas pelo mercado de terras, de energia, de mineração, transportes, logística e outros.

Vivemos um momento particularmente complexo e delicado, em que a eliminação do outro é autorizada até mesmo por um chefe de estado, que ao exaltar um nacionalismo tacanho, desnacionaliza cidadãos e transforma-os em algozes do crescimento econômico e do desenvolvimento. Os que não servem ao mercado de nada servem, são empecilhos a um projeto cujos protagonistas têm cada vez mais autoridade para "acabar com tudo isso que tá aí", contribuindo para um quadro de agravamento das múltiplas violências que acometem os povos do campo. Se o panorama já demonstrava preocupação em momentos anteriores da história, quando empresários e latifundiários deitavam e rolavam com privilégios desde sempre concedidos num país visceralmente moderno-colonial, o enredo hoje ganha contornos dramáticos, sem previsão de tréguas. Apesar deste artigo se centrar em dados referentes aos conflitos no ano de 2017, ano imediatamente posterior ao golpe de estado - quando houve um número alarmante de chacinas e conflitos no campo - a tendência de continuidade de violência se manteve nos anos de 2018 e 2019, conforme relatórios da CPT já divulgados.

Fronteiras do progresso? Modernização do Norte e do Nordeste? Projetos de desenvolvimento? Terá Euclides de Carli realmente comprado o futuro? De quem? Será possível comprar futuros ou destruí-los? Na sanha do agronegócio, do neoxtrativismo representado pelas atividades mineradoras e de exploração energética, do capital especulativo internacional sobre as terras, o Brasil se vê inundado pelo fascismo e a terra embebida de sangue, de luto e de dor. "Quantos mais terão que morrer para que essa 
guerra acabe?". Essa foi a indagação feita pela vereadora do Rio de Janeiro Marielle Franco, um dia antes da noite de 14 de março de 2018, quando foi assassinada, pergunta que ainda permanece sem resposta.

\section{REFERÊNCIAS}

ALMEIDA, Alfredo Wagner B. de. Agroestratégias e desterritorialização: direitos territoriais e étnicos na mira dos estrategistas dos agronegócios. In: ALMEIDA et al. Capitalismo globalizado e recursos territoriais: fronteiras da acumulação no Brasil contemporâneo. Rio de Janeiro: Lamparina, 2010, p. 101-144.

AMAZÔNIA REAL. Coordenadora do MAB é morta com requinte de crueldade no Pará. Moisés Sarraf, 22 de março de 2019. Disponível em: http://abre.ai/ZW4.

ANDES-SN. Chacina no Mato Grosso deixa nove trabalhadores rurais mortos. 25 de abril de 2017. Disponível em: https://goo.gl/RdmmW0. Acesso em: maio de 2016.

BARCELOS, Eduardo. Das normas do território: o Licenciamento ambiental como problema político. Pós Geo UFF, 2017. No prelo.

BECKER, Bertha. Significância contemporânea da fronteira: uma interpretação geopolítica a partir da Amazônia brasileira. IN: AUBERTIN, Catherine et al. (org.). Fronteiras. Brasília: Editora Universidade de Brasília; Paris: ORSTOM, 1988, p.60 89.

BRASIL DE FATO. Dez camponeses são assassinados no Pará: presidenta do sindicato é uma das vítimas. 24 de maio de 2017. Disponível em:

https://goo.gl/z2yEKP. Acesso em: 24 de maio de 2017.

BRASIL DE FATO. Massacre em assentamento deixa pelo menos oito mortos no interior do Mato Grosso. 21 de abril de 2017. Disponível em: https://goo.gl/TaKCsK. Acesso em: maio de 2016.

CANDIDO, Antonio. Os Parceiros do Rio Bonito: Estudo sobre o caipira paulista e a transformação dos seus meios de vida. $11^{a}$ edição. Ouro Sobre Azul: Rio de Janeiro, 2010 .

CASTRO, Luís Felipe P. de; HERSHAW, Eva; SAUER, Sérgio. Estrangeirização e internacionalização de terras no Brasil: oportunidades para quem? EI - Estudos

Internacionais. Belo Horizonte, ISSN 2317-773X, v.5 n.2, p.74 - 102,2017.

COMISSÃO PASTORAL DA TERRA. Atlas de conflitos na Amazônia. Goiânia: CPT Nacional; São Paulo: Entremares, 2017, 104 p.

COMISSÃO PASTORAL DA TERRA. Cacique Babau e Teity Tupinambá passam para prisão domiciliar, na Bahia. 12 de abril de 2016. Disponível em: http://goo.gl/kqgQaM. Acesso em: maio de 2016. 
COMISSÃO PASTORAL DA TERRA. Conflitos no campo Brasil 2017.

[Coordenação: Antônio Canuto, Cássia Regina da Silva Luz, Thiago Valentim Pinto Andrade]. Goiânia: CPT Nacional, Brasil, 2017. 280 p. Disponível em: https://goo.gl/6Nt2kn. Acesso em: maio de 2017.

COMISSÃO PASTORAL DA TERRA. Corpo de liderança Kaiowá é encontrado às margens de rodovia no MS. 03 de novembro de 2014. Disponível em: http://goo.gl/AVuN7U. Acesso em: maio de 2016.

CONGRESSO EM FOCO. Ataque à grupo de índios deixa vítimas com mãos decepadas no Maranhão. 1 de maio de 2017. Disponível em: https://goo.gl/ysPgKF. Acesso em: maio de 2016.

CONSELHO INDIGENISTA MISSIONÁRIO. Com acusações contraditórias, PM prende cacique Babau Tupinambá e o irmão na Bahia. 07 de abril de 2016. Disponível em: http://goo.gl/l82Pmy. Acesso em: maio de 2016.

CONSELHO INDIGENISTA MISSIONÁRIO. Indígenas Gamela tiveram membros do corpo decepados durante ataque no MA; sobre o número de baleados e feridos. 1 de maio de 2017. Disponível em: https://goo.gl/LiIcSs. Acesso em: maio de 2016.

CONSELHO INDIGENISTA MISSIONÁRIO. Povo Gamela retoma nova fazenda no Maranhão. 2 de dezembro de 2015. Disponível em: https://goo.gl/cCn6Dy. Acesso em: maio de 2016.

FIAN INTERNATIONAL. REDE SOCIAL DE JUSTIÇA E DIREITOS HUMANOS. COMISSÃO PASTORAL DA TERRA. Os Custos Ambientais e Humanos do Negócio de Terras: O caso do MATOPIBA, Brasil (relatório). Junho de 2018, 96p.

FOWERAKER, Joe. A luta pela terra: a economia política da fronteira pioneira no Brasil de 1930 aos dias atuais. [Trad. Maria Júlia Goldwasser]. Rio de Janeiro: Zahar, 1982. $315 \mathrm{p}$.

INSTITUTO HUMANITAS UNISINOS. Expectativa de hidrelétrica aumenta ameaças a assentados. 06 de maio de 2016. Disponível em: http://goo.gl/1JHG1W. Acesso em: maio de 2016.

MIGNOLO, Walter. A colonialidade de cabo a rabo: o hemisfério ocidental no horizonte conceitual da modernidade. IN: LANDER, E. A colonialidade do saber: eurocentrismo e ciências sociais. Perspectivas latino-americanas. Buenos Aires: CLACSO, 2005. pp 71 - 103. Disponível em: 〈http://goo.gl/tp5uOD>.

O GLOBO. Bolsonaro defende que áreas quilombolas possam ser vendidas. 6 de julho de 2018. Disponível em: <https://oglobo.globo.com/brasil/bolsonaro-defende-queareas-quilombolas-possam-ser-vendidas-22859321>. 
PEREIRA, Carolina de Freitas. As Agroestratégias Ruralistas de

Desterritorialização de Povos Indígenas e Quilombolas: (Re)definindo Marcos Legais e Usos Territoriais. 2018. Tese (doutorado) - Universidade Federal Fluminense, Niterói, 326 f. Niterói, 2018.

PORTO-GONÇALVES, Carlos Walter. Geografia da violência no campo brasileiro: O que dizem os dados de 2003. Revista Crítica de Ciências Sociais, 75, Outubro 2006: 139-169.

PORTO-GONÇALVES, Carlos Walter; QUENTAL, Pedro de A. América Latina e a Colonialidade do Poder. IN: Globalização e fragmentação no mundo contemporâneo. Niterói: Editora da UFF, 2ed, 2013, pp. 167-192.

PRAGMATISMO POLÍTICO. Corpo de ativista é achado com mãos e braços amarrados a pedras pesadas. 23 de junho de 2016. Disponível em: http://abre.ai/ZXu.

QUIJANO, Aníbal. Colonialidade do poder, eurocentrismo e América Latina. IN: LANDER, E. A colonialidade do saber: eurocentrismo e ciências sociais. Perspectivas latino-americanas. Buenos Aires: CLACSO, 2005. pp 227 - 278. Disponível em: <http://goo.gl/O4o3F8>.

REPÓRTER BRASIL. Em terras alheias: A produção de soja e cana em áreas Guarani no Mato Grosso do Sul. Centro de monitoramento de Agrocombustíveis, 2013. Disponível em: < https://reporterbrasil.org.br/documentos/emterrasalheias.pdf>.

REPÓRTER BRASIL. Filantropo em São Paulo, empresário é acusado de mortes e roubo de terras no Nordeste. Daniel Camargos, 2 de setembro de 2018. Disponível em: <https://reporterbrasil.org.br/2018/09/empresario-euclides-de-carli-acusado-mortesroubo-terras-nordeste/ $\geq$

SAUER, Sérgio. Demanda mundial por terras: "land grabbing" ou oportunidade de negócios no Brasil? Revista de estudos e pesquisas sobre as Américas, v. 5, nº 1 , 2010.

SURVIVAL BRASIL. O que Jair Bolsonaro, Presidente-eleito, disse sobre os povos indígenas do Brasil. 2019. Disponível em:

<https://www.survivalbrasil.org/artigos/3543-Bolsonaro>

VELHO, Otávio Guilherme. Capitalismo autoritário e campesinato: um estudo comparativo a partir da fronteira em movimento. São Paulo - Rio de Janeiro: Centro Edelstein de Pesquisas Sociais, 1979 [2009].

VELHO, Otavio Guilherme. Frentes de expansão e estrutura agrária: estudo do processo de penetração numa área da Transamazônica. Rio de Janeiro: Centro Edelstein de Pesquisas Sociais, 1972 [2009].

Recebido em 29/07/2020.

Aceito para publicação em 16/10/2020. 